\title{
Impacts of recent climate change on wheat production systems in Western Australia
}

\author{
Fulco Ludwig • Stephen P. Milroy • Senthold Asseng
}

Received: 14 November 2006 / Accepted: 12 May 2008 / Published online: 10 September 2008

(C) The Author(s) 2008. This article is published with open access at Springerlink.com

\begin{abstract}
The wheatbelt of Western Australia shows a distinct Mediterranean climate with most of the rainfall occurring in the winter months. The main factor limiting plant production in this region is rainfall. Due to clearing of native vegetation, dryland salinity is a major problem in south-west Australia. Since the mid 1970s the region has experienced a significant decrease in winter rainfall. Across nine sites, growing season rainfall (May to October) decreased by an average of $11 \%$ and the sum of rainfall in June and July (June + July) decreased by $20 \%$. We used the ASPIM-Nwheat model in combination with historic climate data to study the impact of recent climate change on the hydrology and production of wheat based farming systems by comparing results for before and after 1975. Despite the large decline in rainfall, simulated yields based on the actual weather data did not fall. At the same time, simulated drainage decreased by up to $95 \%$ which will significantly reduce the spread of dryland salinity. These results were due to the rainfall changes mainly occurring in June and July, a period when rainfall often exceeds crop demand and large amounts of water are usually lost by deep drainage. The findings will have significant implications for estimates of future climate change impacts in this region with changes in rainfall causing non-proportional impacts on production and hydrological aspects, such as deep drainage and waterlogging, where proportionality is often presumed.
\end{abstract}

F. Ludwig · S. P. Milroy · S. Asseng

CSIRO Plant Industry, Private Bag No. 5, Wembley, WA 6008, Australia

Present Address:

F. Ludwig $(\bowtie)$

Earth System Science and Climate Change group, Wageningen University and Research

Centre, P.O. Box 47, 6700 AA, Wageningen, The Netherlands

e-mail: Fulco.Ludwig@wur.nl 


\section{Introduction}

In south-west Australia, about 5 million hectares are planted to wheat (Triticum aestivum L.) each year. Wheat is mainly grown in areas with an average yearly rainfall of between 280 and $550 \mathrm{~mm} /$ year. The region shows a distinct Mediterranean climate with cool, wet winters and hot, dry summers. Over $75 \%$ of the rain falls between May and October. This period is generally recognised as the growing season for annual field crops. It is usually considered that the main factor limiting plant production in this region is rainfall (Turner and Asseng 2005).

Since the mid 1970s this area has experienced a significant decline in winter rainfall (Smith et al. 2000; IOCI 2002). This decline in rainfall was associated with, and probably caused by, a large scale change in global atmospheric circulation during the mid 1970s (IOCI 2002).

The drop in rainfall has had significant impacts on the water sector in Western Australia (WA). For example, the water inflow into dams surrounding Perth has declined by about 50\% (Power et al. 2005). While the impact of the drying trend on the water sector is very clear, the impacts on the agricultural sector are less well understood. As most of the agriculture in WA is rainfall limited most have assumed that a drying trend would also have a negative impact on crop production. However, despite the lower rainfall, average wheat grain yield in the Western Australian wheatbelt has continued to increase over the last decades. Between 1930 and 1980 wheat yields in West Australia increased from about $0.7 \mathrm{t} / \mathrm{ha}$ to about $1.1 \mathrm{t} / \mathrm{ha}$, an average increase of $7 \mathrm{~kg} \mathrm{ha}^{-1}$ per year (Turner and Asseng 2005). Between 1980 and 2000 yields increased from 1.1 to $1.7 \mathrm{t} / \mathrm{ha}$ which is an average increase of $40 \mathrm{~kg} \mathrm{ha}^{-1}$ per year. So despite the lower rainfall, the rate of increase in yields has been higher during the last two decades than in previous periods. To estimate the impact of the changes in climate, it is necessary to remove the overriding influence of technological change.

Changes in rainfall are not only likely to affect agricultural production but also the hydrology of the systems. Over the last century, clearing of a large proportion of the native vegetation for the production of annual crops has resulted in increased deep drainage (Turner and Ward 2002). Higher deep drainage rates in annual cropping systems causes the groundwater level to rise, bringing salt to the surface and thus making large parts of the landscape unsuitable for cropping (George et al. 1997). McFarlane and Williamson (2002) estimated that about $10 \%$ of cropping land in south-west Australia is affected by dryland salinity which could increase to up to $30 \%$ in the coming decades. As a consequence of this prediction, large investments are currently being made to minimise the impact of dryland salinity in south-west Australia. However, deep drainage is highly correlated with annual rainfall (Asseng et al. 2001) and any reduction in rainfall could potentially reduce deep drainage and the spread of dryland salinity. Noticeably, the spread of dryland salinity over the last decade has already been less than initially predicted and groundwater levels have declined in parts of the wheatbelt (McFarlane et al. 2004; McFarlane and Ruprecht 2005).

Leaching of nutrients is a cost to the producer and also presents the possibility of ground water contamination. There are relatively few estimates of nitrate leaching in 
the northern half of the WA wheatbelt. At Moora, measurements of leaching below wheat over 3 months spanning the period when most deep drainage is likely, varied between 24 and $59 \mathrm{~kg} / \mathrm{ha}$ of $\mathrm{N}$ (Anderson et al. 1998). Asseng et al. (1998a), using the APSIM-NWheat simulation model, estimated the median annual nitrate leaching under wheat following lupins to be $53 \mathrm{~kg} / \mathrm{ha}$ of $\mathrm{N}$. At a current cost of over Australian $\$ 1 / \mathrm{kg}$ of $\mathrm{N}$ applied as urea, this represents a significant proportion of growers input costs.

When examining trends in historic grain yield data (e.g., Hamblin and Kyneur 1993), it is difficult to separate the effect of climate change on crop production or hydrology from the effects of changes in land use, varieties and crop management (Magrin et al. 2005). The use of a simulation model makes it possible to study the impact of changes in the climate while keeping other technology variables (like cultivars and management) constant. The Agricultural Production Systems Simulator (APSIM; Keating et al. 2003) has been rigorously tested and used to estimate both deep drainage and grain yields for different crops (e.g. Keating et al. 1995; Probert et al. 1995; Asseng et al. 1998a). The APSIM-Nwheat model, in particular, has been extensively validated for south-west Australia (Asseng et al. 1998a, b). We used the ASPIM-Nwheat model in combination with historic climate data to study the impact of recent climate change on wheat cropping. We estimated how the drying climate has affected crop production and hydrology of farming systems in Western Australia. We also examined whether, due to a change in climate, growers should change their nutrient inputs to maximize their gross margins.

\section{Methods}

\subsection{Site descriptions}

Nine sites were selected within the central and northern parts of the WA wheatbelt. The nine sites covered both the high and low rainfall parts and the warmer and cooler parts of the region (Fig. 1). For all sites, daily rainfall data were available from at least 1945 until 2004. Weather data for all sites were downloaded from the from patched point dataset on the Silo website (http://www.bom.gov.au/silo). We analysed the impact of recent climate change on different variables by comparing two different periods: (1) 1945-1974 and (2) 1975-2004. These two sets of years were selected because of the large step change in atmospheric circulation that occurred during the mid 1970s (Smith et al. 2000; IOCI 2002).

Three soil types typical for the region were used for the simulations: (1) a sand, (2) a loamy sand, and (3) a sand over clay duplex soil. Due to the different textures, soils varied in water holding capacities and thus in plant available water holding capacity (PAWC). PAWC for the sand was $55 \mathrm{~mm}$ to a depth of $150 \mathrm{~cm}$, the maximum rooting depth for this soil. For the loam PAWC was $130 \mathrm{~mm}$ to a maximum rooting depth of $230 \mathrm{~cm}$ and PAWC was $81 \mathrm{~mm}$ for the duplex soil to a maximum rooting depth of $70 \mathrm{~cm}$. Full details of the soils are given in Asseng et al. (2001). 
Fig. 1 Map of southwest Australia showing the nine study sites. The shaded part indicates the wheatbelt. Arrows indicate direction of trend of increasing average temperature and average rainfall

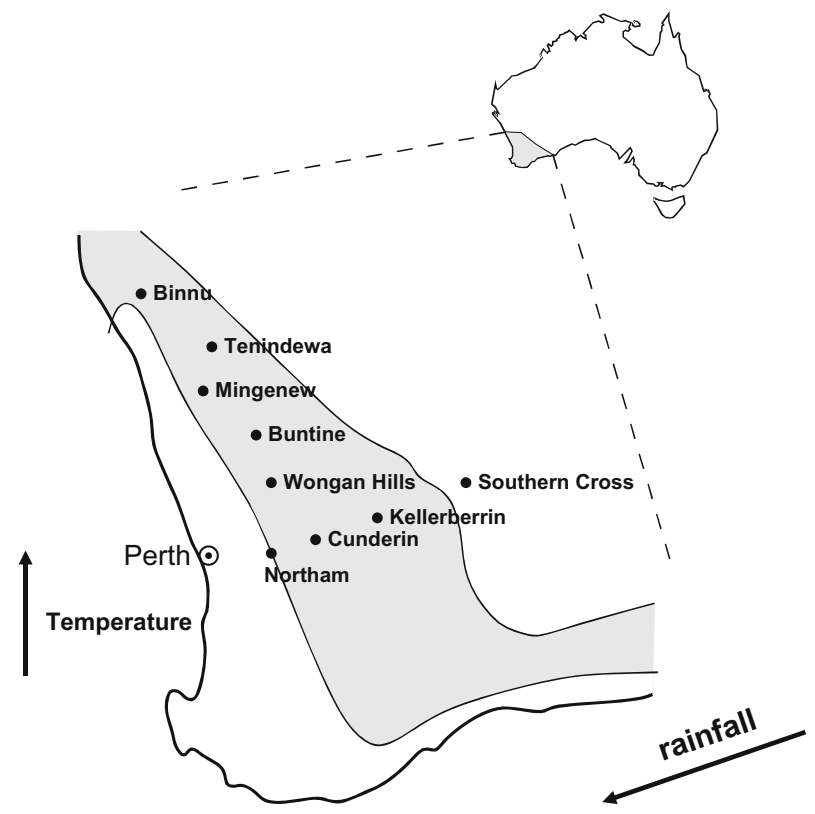

\subsection{The APSIM-Nwheat model}

The Agricultural Production Systems Simulator (APSIM) for wheat (APSIMNwheat version 1.55s) is a crop simulation model consisting of modules that incorporate aspects of soil water, nitrogen, crop residues, crop growth and development and their interactions within a crop/soil system that is driven by daily weather data (Keating et al. 2001). APSIM-Nwheat has been extensively tested against a range of field measurements in particular in the Mediterranean climatic regions of Western Australia (Asseng et al. 1998a, b, 2001; Probert et al. 1995, 1998; Asseng et al. 2000, 2004). Documented model source code in hypertext can be viewed at http://www.apsim.info.

APSIM-Nwheat calculates potential daily biomass production based on light interception and radiation-use efficiency (RUE). Sub-optimal temperatures, water and $\mathrm{N}$-deficit can reduce the potential growth. Potential water demand is a function of transpiration efficiency (TE) modified by vapour pressure deficit (Monteith 1988). Simulated plant water uptake is a function of uptake demand, root length density distribution within the soil profile, and available soil water in different soil layers. Rate of rooting depth advance is a function of air temperature, crop water stress, and soil water content in the soil layer with the deepest roots. Vertical soil water movement is simulated using a multi-layered soil model primarily using a cascading approach, with movement both upward and downward also occurring by diffusive flow (Probert et al. 1998). Water (deficit) stress reduces tillering, LAI and photosynthesis, and enhances senescence.

Grain yield is a function of grain number, grain filling and carbohydrate remobilization. In the model, the potential amount of carbohydrates available for 
remobilization to grain is defined as $75 \%$ of biomass growth between $150 \mathrm{Cd}$ before grain filling and the commencement of grain filling. Crop phenology is a function of accumulated degree-days, photoperiod and vernalisation requirements.

In the model, critical and minimum crop $\mathrm{N}$ concentrations are a function of growth stage. Crop $\mathrm{N}$ demand is the difference between critical and actual $\mathrm{N}$ content plus the $\mathrm{N}$ amount required for new growth on a given day. When $\mathrm{N}$ concentration falls below the critical concentration, a $\mathrm{N}$ stress factor $\left(F_{N}\right)$ is calculated based on the ratio of actual and critical $\mathrm{N}$ concentration. $\mathrm{N}$ stress reduces leaf area growth, tillering (when $F_{N}<1.0$ ), photosynthesis (when $F_{N}<0.66$ ) and increases leaf area senescence (when $F_{N}<0.66$ ) and root-shoot ratio for carbon partitioning (when $F_{N}<1.0$ ). Nitrogen uptake follows the approach of the CERES-Wheat model (Ritchie et al. 1995) and is a function of potential $\mathrm{N}$ uptake capacity of the root systems and crop $\mathrm{N}$ demand. The potential $\mathrm{N}$ uptake capacity is a function of root length density distribution, soil nitrate and ammonium concentrations and soil water content. Deep drainage is defined as water leaving the potential maximum rooting depth of a wheat crop on a specific soil (see Asseng et al. 2001).

A modified version of SOILWAT2 which handles the dynamics of perched water tables (Asseng et al. 1997, 2001) was used for the simulations to allow for waterlogging in the duplex soil. The modified version includes a new parameter that controls the flow rate of water through macropores, a process that is not controlled in the multi-layer cascading approach (Probert et al. 1998). The inclusion of this parameter enabled soil layers to remain saturated over extended periods of time and a perched water table in the profile could then be quantified as the proportion of the water content between drained upper limit (DUL) and saturation (SAT) in a layer, when the next layer below is saturated. If a perched water table rises into the rooting zone, crop and root growth is reduced (Asseng et al. 1997, 2001).

\subsection{Configuration of simulations}

The model was run using historic daily weather data for the periods 1945-1974 and 1975-2004 to assess the impact of the actual change in weather. At each of the nine sites grain yield, deep drainage and nitrate-N leaching were simulated on the three different soils (sand, loam and duplex). Daily weather data used in the simulations were rainfall, maximum and minimum temperatures, and solar radiation. For all simulations soil $\mathrm{N}$ and water contents were re-set every year on 1 January to a dry soil profile and a total of $50 \mathrm{~kg}$ mineral $\mathrm{N} \mathrm{ha}^{-1}$. Sowing date depended on the start of the autumn rains. There were two phases to the sowing window. In the first, the late maturing variety Spear was sown if rainfall was at least $10 \mathrm{~mm}$ over the previous 10 days and the water content in the topsoil $(5-10 \mathrm{~cm})$ was at least $50 \%$ of plant available water. The earliest sowing date possible was 5 May. If a sowing opportunity did not occur before 5 June then the early maturing variety Amery was planted if rainfall was at least $10 \mathrm{~mm}$ over the previous 10 days regardless of the soil water content. Sixty $\mathrm{kg} \mathrm{N} \mathrm{ha}^{-1}$ as urea fertilizer was applied at sowing which is about the current average fertilizer usage by farmers across the area covered by the simulation sites.

Further simulations were run using synthetic weather files to allow an evaluation of the extent to which the timing of the rainfall reduction within the growing season 
was important for yield (see below for description of these weather files). These simulations were only done for the loamy soil using the same sowing rules and fertilizer treatment as the other simulations.

\subsection{Derivation of synthetic weather files}

The impact of a given reduction in rainfall $(\mathrm{mm})$ on final yield will depend on the time of year at which the reduction occurs. To examine the sensitivity of yield to the timing of a rainfall reduction, we constructed synthetic weather data sets based on the actual climatic records for the period 1945-1974. This period was chosen to allow us to compare the impacts of the artificial reductions in rainfall to that of the observed reduction to the lower rainfall period of 1975-2004. Firstly, rainfall was reduced by $10 \%$ during the growing season (May to October) by reducing every rainfall event by $10 \%$. A second synthetic weather file was created by reducing rainfall only in June and July because rainfall in south-west Australia has mostly decreased in these 2 months (see Fig. 2). The reduction in the amount of rainfall was kept equal to the $10 \%$ reduction in growing season rainfall but this time the rain was only reduced in June and July. For example, if in a given year and site the June rainfall plus July rainfall was $120 \mathrm{~mm}$ and the seasonal rainfall was $240 \mathrm{~mm}$, the June + July rainfall would have been reduced by $24 \mathrm{~mm}$, which in this case was $20 \%$ for the 2 months. This rainfall was reduced by subtracting $20 \%$ from each rainfall event in June and July. A third set of weather files was created reducing rainfall only in May, June, July or August alone. The same procedure was used as for the reduction in June and July rainfall. In addition, synthetic weather files were constructed by reducing the seasonal rainfall by $20 \%$ and subsequently using the same amount of rainfall reduction only decreasing rainfall in June and July.

\subsection{Determining optimal $\mathrm{N}$ fertilizer management}

When using simulation models for decision support systems (e.g. Hochman et al. 2008; Carberry et al. 2002), or other analyses (e.g. Asseng and Van Herwaarden 2003) all available historic weather data are usually used. To test whether the recent climate change in south-west Australia means a shorter time frame of weather data should be used for decision support systems, we determined optimal $\mathrm{N}$ fertilizer treatments for each of the nine site and three soil types for the two different periods, 1945-1974 and 1975-2004.

The optimal $\mathrm{N}$ fertilizer treatment amount was defined as the amount of $\mathrm{N}$ fertilizer which resulted in the highest average gross margin for the 30 year period. For each of the nine locations and three soil types, simulations were run for both periods using ten different $\mathrm{N}$ treatments: $0,20,40$, etc. to $180 \mathrm{~kg} \mathrm{~N} \mathrm{ha}^{-1}$. In all cases the $\mathrm{N}$ application was split with half the amount added at sowing and the other half at 7 weeks after sowing. Gross margin was defined as grain yield $\times$ grain price (being a function of grain $\mathrm{N}$ concentration) less variable costs. Variable costs excluding $\mathrm{N}$ fertiliser were taken as Australian $\$ 120$ per hectare (Ludwig and Asseng 2006). Fertiliser costs (including application) were taken as Australian $\$ 1 / \mathrm{kg} \mathrm{N}$. For Western Australia, the relationship between grain price (GP in Australian dollar per 


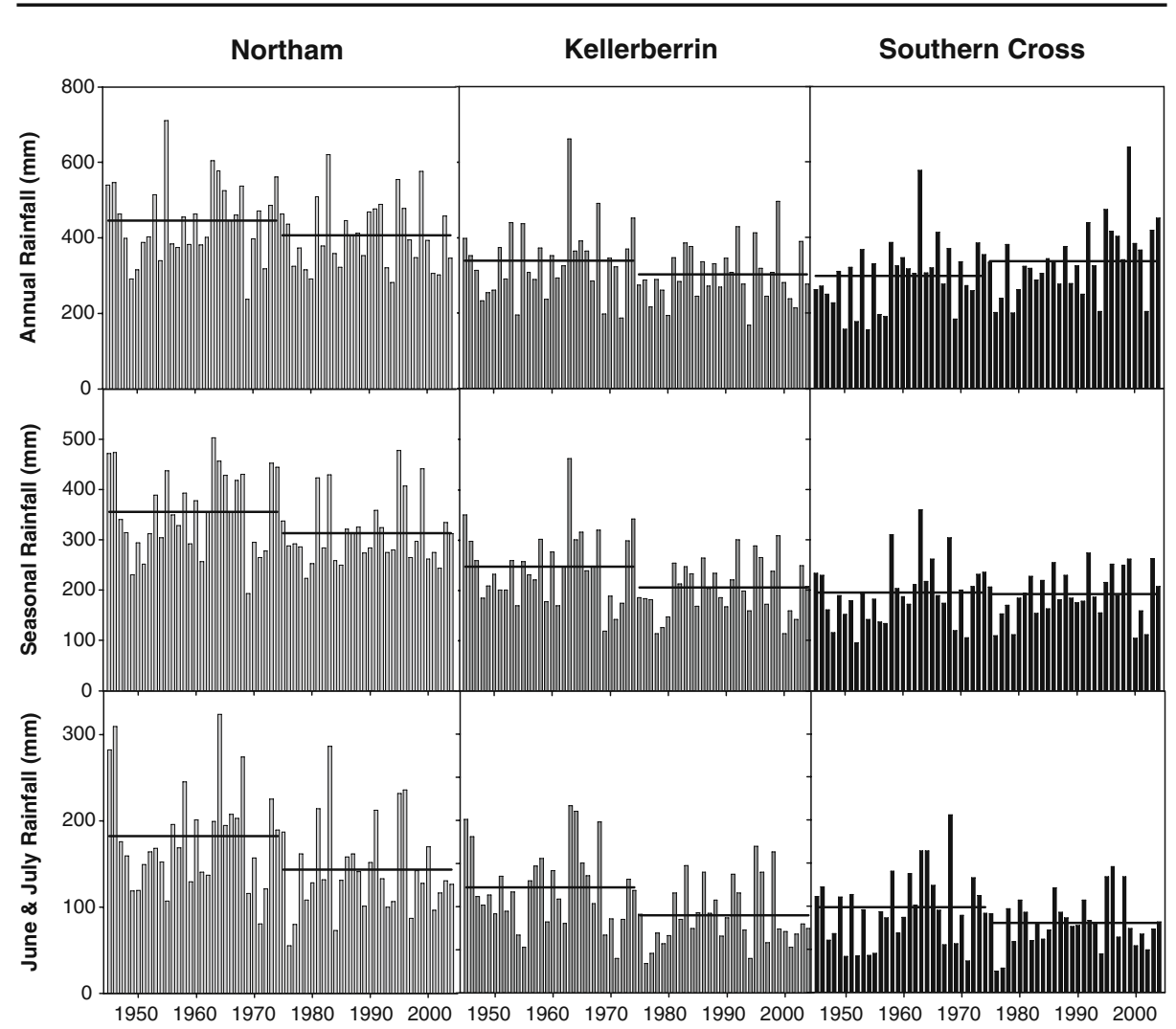

Fig. 2 Time series of annual, seasonal (May to October), and June and July rainfall for three locations within the West Australian wheatbelt. Lines indicate the average rainfall for the 1945-1974 and the 1975-2004 periods

ton grain) and the $\mathrm{N}$ concentration ( $\mathrm{NC}$ in \%) in the kernels has been estimated by Howden et al. (1999) based on data from 1994-1999 as:

$$
\begin{array}{ll}
\mathrm{GP}=-66.498 \mathrm{NC}^{3}+436.17 \mathrm{NC}^{2}-852.4 \mathrm{NC}+657.31 & \text { if } \mathrm{NC}<2.6 \%, \text { and } \\
\mathrm{GP}=219.04 & \text { if } \mathrm{NC}>2.6 \%
\end{array}
$$

\subsection{Data analyses}

Differences in rainfall and simulated yield between the two different periods (19451974 and 1975-2004) were tested separately for each site using a one-way ANOVA. Difference in nitrate-N leaching and deep drainage could not be tested with ANOVA because of differences in variance between the data from the two different periods. Instead, a Mann-Whitney $U$ test was used. To test if drainage was differently related to rainfall in the two different periods we did a regression analyses with rainfall as the independent factor and drainage as the dependent factor. Difference in the slope 
or intercept of the regression line between the pre- and post-1975 periods was tested using forward stepwise regression, adding the time period as a factor.

\section{Results}

Comparing annual temperatures before and after 1975, there was no difference in either average daily maximum or average daily minimum temperature for any month or for the growing season as a whole.

\subsection{Changes in rainfall}

Annual rainfall tended to be lower after than before 1975, most locations have experienced a reduction in a rainfall (Table 1; Fig. 2). Due to the high year to year variability in rainfall the reduction in annual rainfall was only statistically significant $(P<0.05)$ at Mingenew. Reductions in annual rainfall ranged from $4 \%$ to $13 \%$ with the exception of Southern Cross, which has seen an increase of $13 \%$. Since most of the reduction in rainfall has occurred during the winter months, particularly in June and July (Figs. 2 and 3), the proportional reductions in growing season rainfall have been greater, ranging from $7 \%$ to $17 \%$ and reaching significance at five of the nine sites $(P<0.05$; Table 1). Again Southern Cross was the exception with effectively no change in growing season rainfall. Across the nine sites the reduction in growing season rainfall averaged $11 \%$ with the reduction in June and July rainfall averaging $20 \%$. The reduction in June to July rainfall was significant at all sites except Southern Cross (Table 1). At most locations, there has been a shift in the rainfall pattern with the highest monthly rainfall occurring later in the growing season (Fig. 3). The year to year variability in rainfall has also changed; the standard deviation for the rainfall was generally lower in the 1975-2004 period than for the 1945-1974 period (Table 1). However, this difference reflected the change in the mean: the relationship between the average rainfall and standard deviation did not differ significantly between the two periods.

Among the sites used in this study, there was no geographical trend in the magnitude of the reduction in rainfall either along the east-west or the north-south transect. This was the case for both annual and growing season rainfall. The reduction in growing season rainfall was loosely correlated with the pre-1975 rainfall.

\subsection{Impact of rainfall change on crop yield}

Simulated yield based on actual weather records yielded no evidence of a systematic reduction between the pre- and post-1975 periods (Table 2), despite the reduction in rainfall. None of the yield changes were statistically significant. In fact, yields were numerically higher at eight of the nine sites for the duplex soil and at five and six sites respectively for the sand and the loam. On the sand at Wongan Hills, Mingenew and Southern Cross, on the loam at Northam, and on the duplex soil at Southern Cross, the increases in yield reached the marginal level of significance $(P<0.1)$. As was the case with rainfall, there was no trend in the magnitude of the changes along an east-west or a north-south transect for either the absolute or proportional change in grain yield. As for rainfall, differences in the variability of yield (standard deviation, 


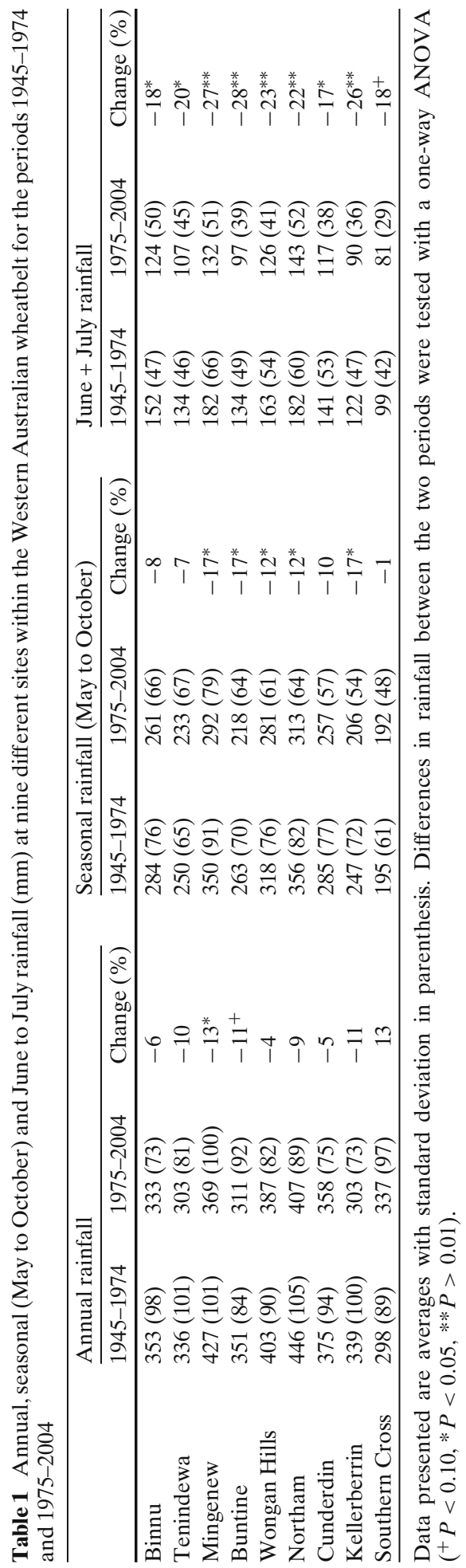




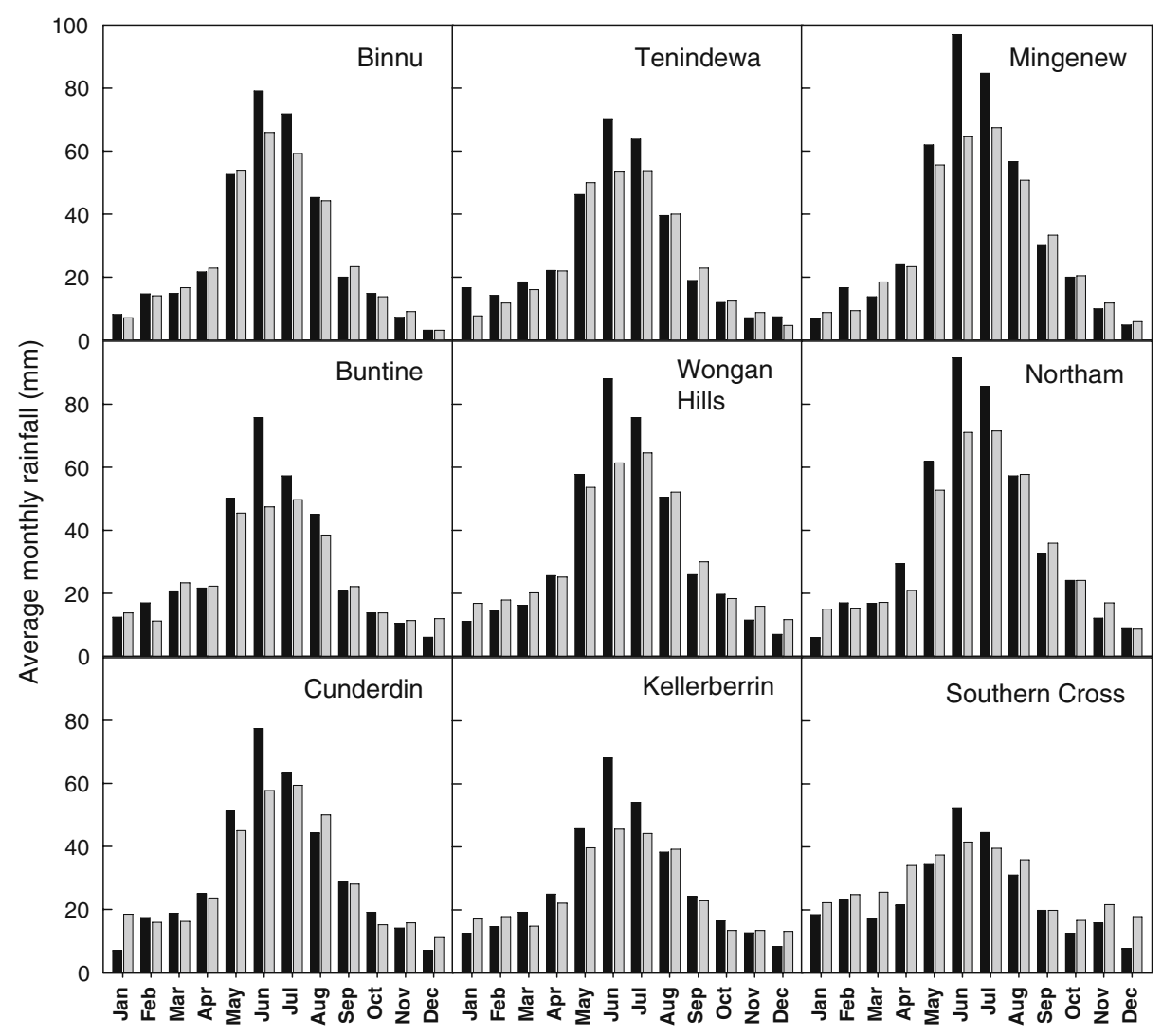

Fig. 3 Observed average monthly rainfall from 1945-1974 (black) and 1975-2004 (grey) for the nine sites within the Western Australian wheatbelt

Table 2) between the pre- and post-1975 periods reflected the change in the average simulated yield.

As indicated earlier, sowing dates were simulated using a sowing rule which depended on rainfall and soil moisture. The differences in rainfall between the preand post-1975 periods did not induce any significant change in sowing date at any location. The average sowing date only changed by a few days, being earlier for some locations and later for others.

\subsection{Impact of rainfall change on drainage, nitrate leaching and waterlogging}

The lower rainfall in the 1975-2004 period resulted in a large reduction in average annual drainage below the maximum root zone (Fig. 4) at all sites except Southern Cross where the drainage increased. The greatest absolute reductions occurred with the sand and the greatest proportional changes with the loam. Reductions were greatest at the three higher rainfall sites of Mingenew, Northam and Wongan Hills but significant reductions also occurred at Buntine, Kellerberrin and Tenindewa. Combining data from all nine sites, it became clear that the relationship between 


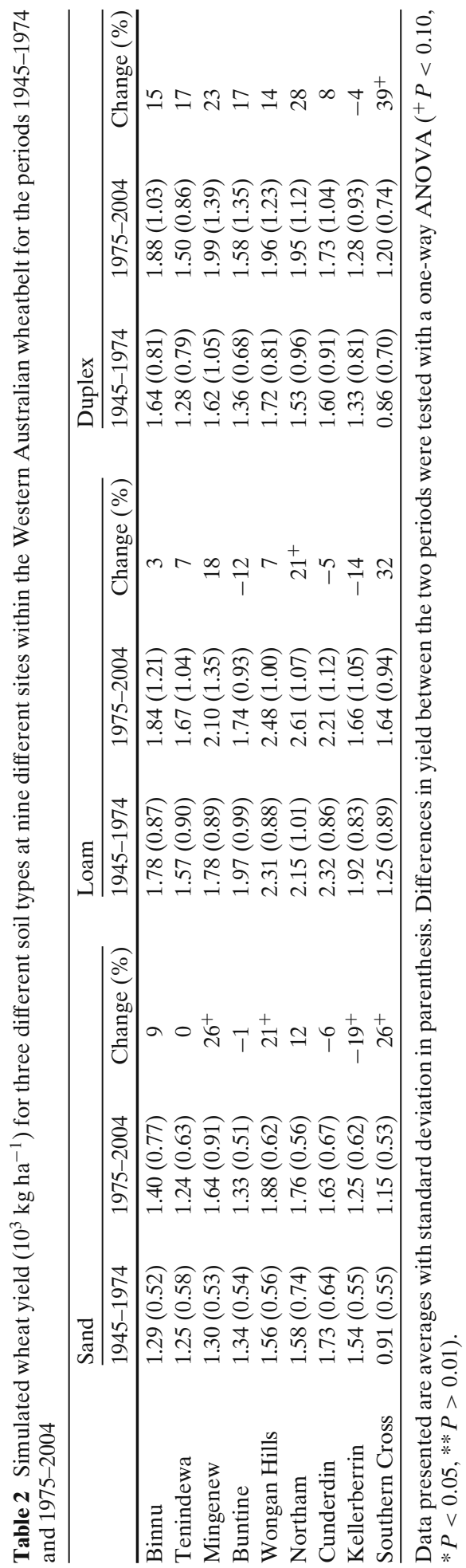


Fig. 4 Simulated average annual deep drainage below the maximum rooting depth from wheat cropping systems for three different soil types for the periods 1945-1974 (black) and 1975-2004 (grey). Differences in drainage between the two periods were tested with a Mann-Whitney $U$ test $(+P<0.10, * P<0.05, * * P>0.01)$

drainage and rainfall differed between the two periods (Fig. 5): for any given annual rainfall, there was less drainage in the post-1975 period. Both the slopes and the intercepts of the regression lines were significantly different $(P<0.001)$ between the two periods.

The simulated reduction in leaching of nitrate-N (Table 3) was similar to the change in drainage. Again, the greatest absolute reductions were for simulations on the sand (10-25 kg/ha) while the greatest proportional reductions were on the loam (65-95\%). Southern Cross differed again, showing an increase in leaching of nitrate$\mathrm{N}$.

As a consequence of rainfall decline, waterlogging has also declined in the last 30 years. For example, simulated waterlogging, expressed as SEW30 (cumulative soil excess water above $30 \mathrm{~cm}$ below the soil surface, after Belford et al. (1991)) declined in the last 30 years between $37-48 \%$ compared to the previous 30 years at Wongan Hills and Northam.

\subsection{Impact of rainfall distribution on yield}

When the rainfall data were artificially altered, reducing the pre-1975 growing season rainfall by $10 \%$, the impact on simulated yield was highly variable depending on the location (Fig. 6a). When the reduction was applied to all rainfall events between May and October the higher rainfall locations of Mingenew and Northam, and to some extent Wongan Hills, showed an increase in yield but in most locations it had a negative impact on yield. For Kellerberrin and Southern Cross, the yield reduction was more than $10 \%$. If the reduction in rainfall was concentrated in June and July, the yield was higher in most cases than when the rainfall reduction was applied across the growing season (seven out of nine sites), however the differences were relatively small (Fig. 6a). Similar patterns exist for the impact of a $20 \%$ reduction in seasonal rainfall except concentrating the reduction in June and July was more markedly beneficial for yield relative to the uniform reduction.

By applying the reduction in rainfall to each of 4 months of the growing season individually, crop yields were shown to be relatively less sensitive to reductions in June or July and more sensitive in reductions in May or August (Fig. 6b). Reducing rainfall in May or August decreased yield at all sites. At the sites with highest annual rainfall, reducing rainfall in June or July slightly increased yield. At the other sites, reducing rainfall in June or July had a less negative effect on yield than when rainfall was reduced in May. At all sites except Northam and Cunderdin, yield was reduced the most if rainfall was reduced in May. As we used a flexible sowing rule reducing rainfall in May generally delayed sowing which often reduced yields. Therefore, reducing rainfall in May affected yield both through decreasing crop available water and due to a shorter growing season. 


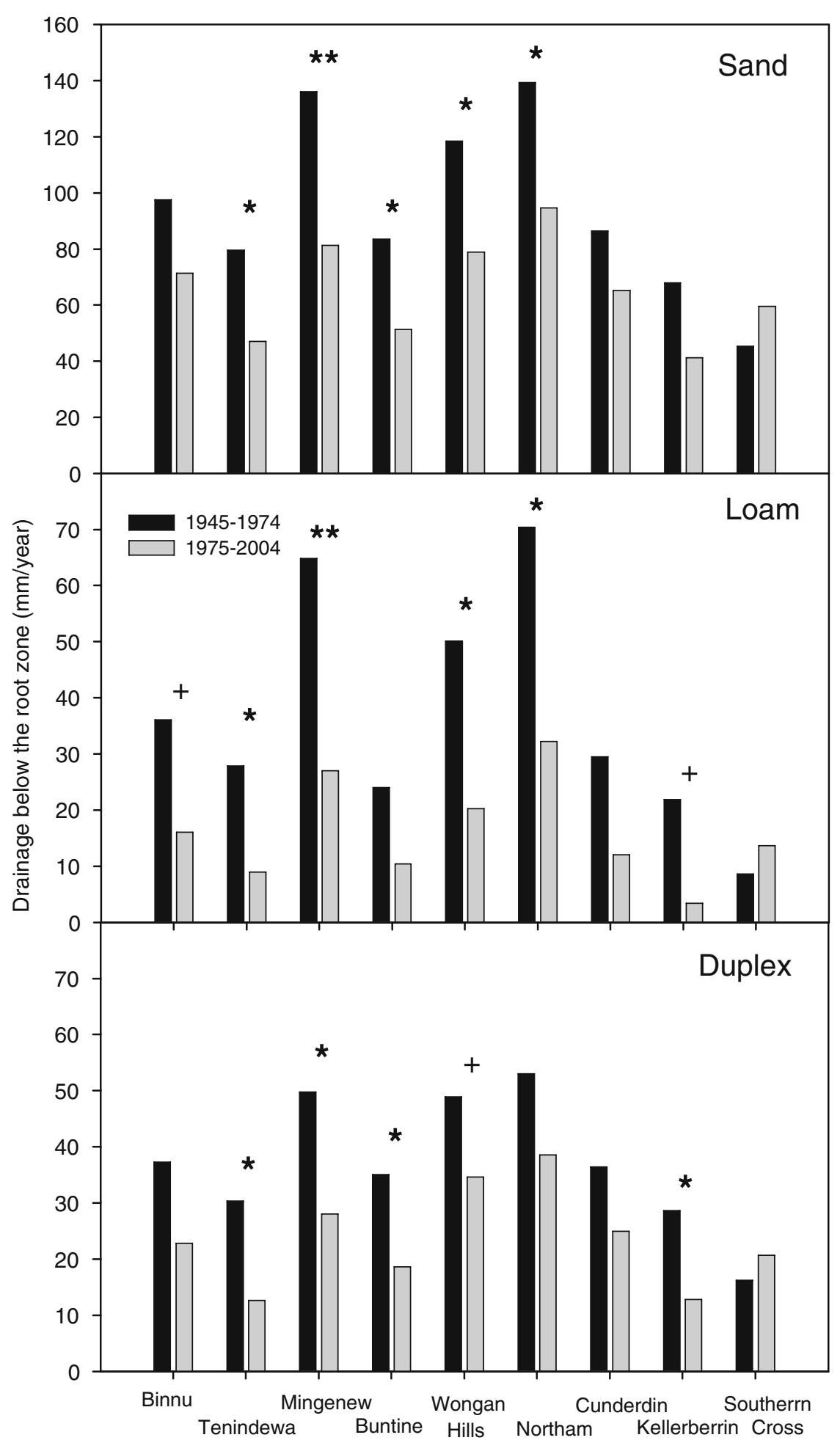




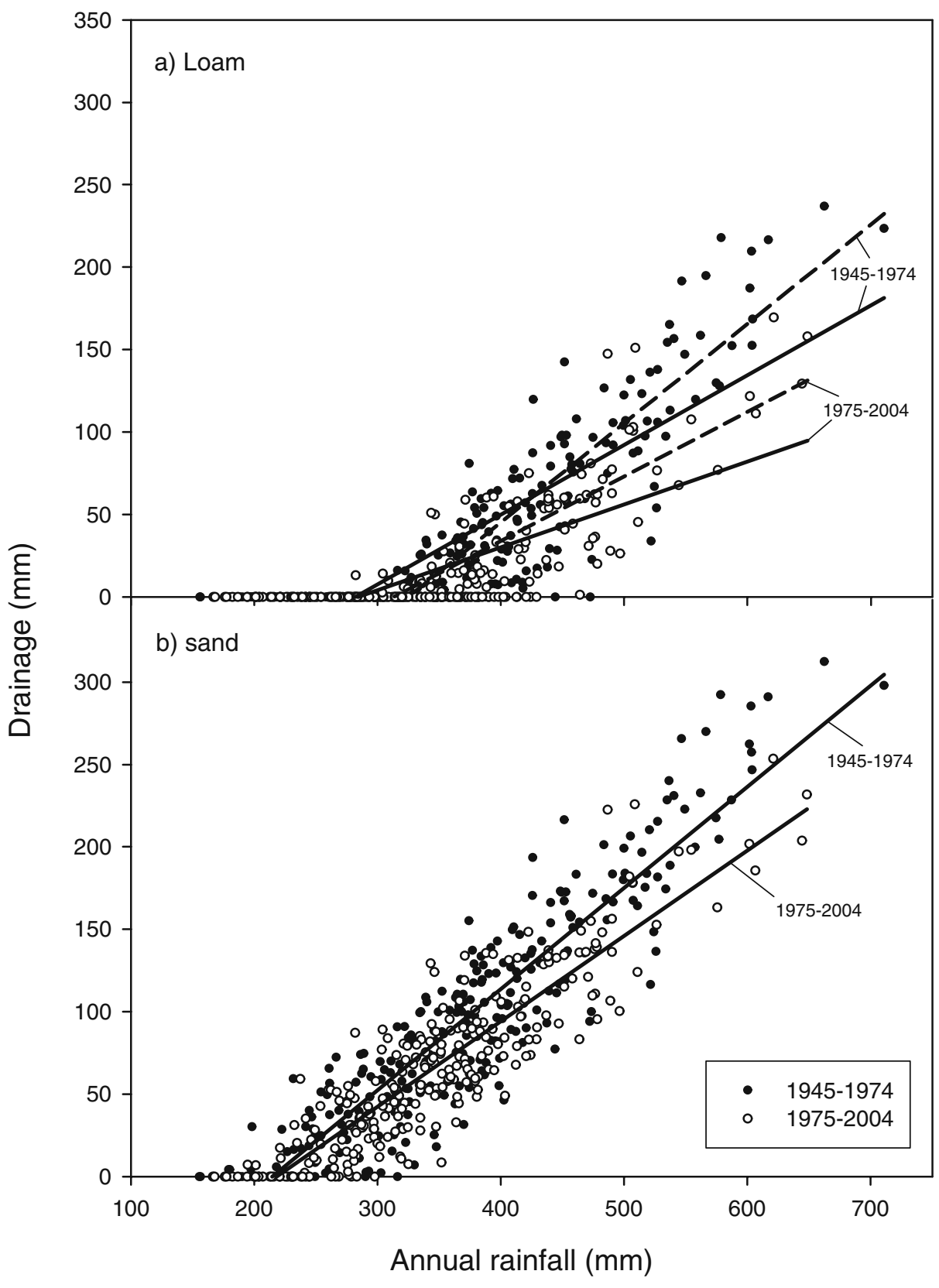

Fig. 5 Relationship between measured annual rainfall and simulated deep drainage for 1945-1974 (filled circles) and 1975-2004 (open circle) on sand and loam soils. All data from the nine sites are presented. The solid lines represent a regression using all data for each period and the dashed lines represent the regression using only drainage numbers $>1 \mathrm{~mm} / \mathrm{year}$ 


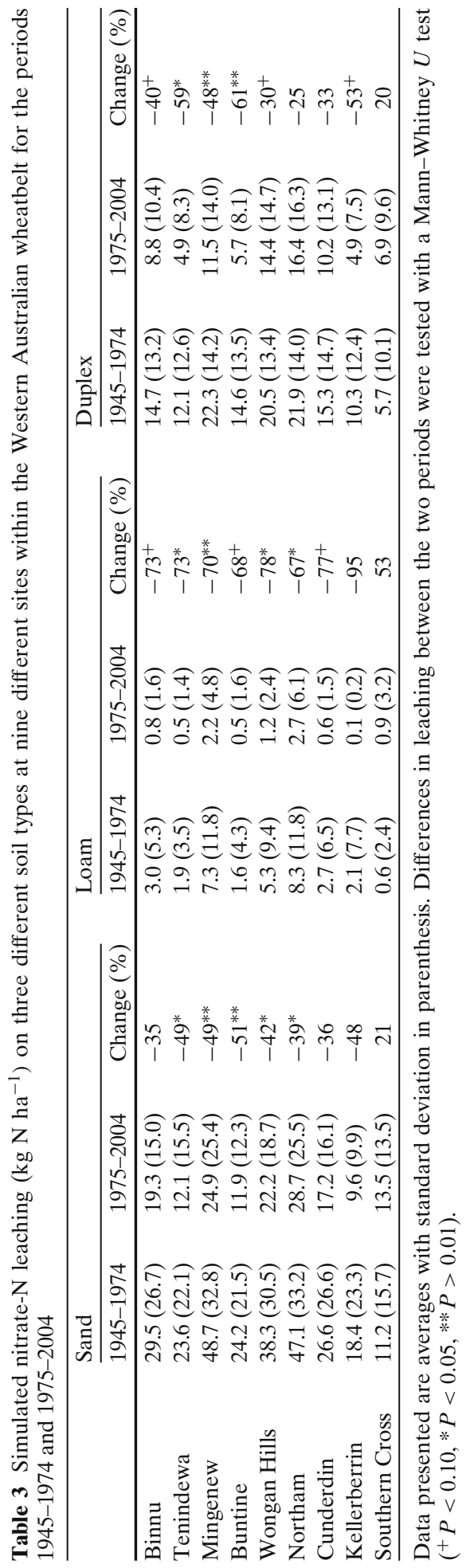




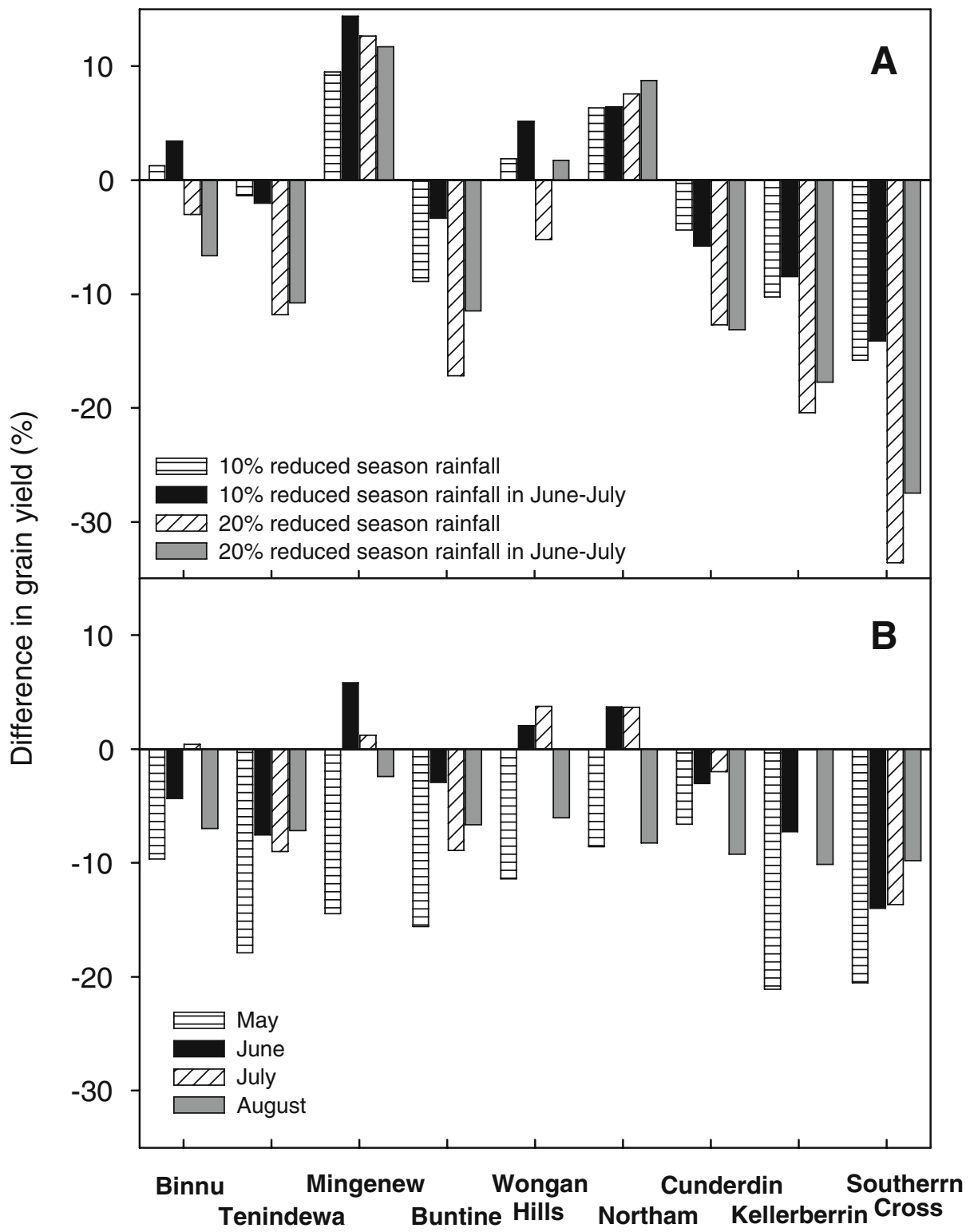

Fig. 6 Impact of rainfall changes on simulated wheat yield: a simulated yield impact of changes in rainfall at different times in the growing season (10\% reduction in growing season rainfall; horizontal lines in bar), $10 \%$ reduction in growing season rainfall applied to June to July (black bars), 20\% reduction in growing season rainfall (diagonal lines in bar) and 20\% reduction in growing season rainfall applied to June to July (grey bars); b impact of a $10 \%$ reduction in rainfall applied to a single month (May, June, July and August). Impact is shown relative to simulated yields with unmodified rainfall 
3.5 Gross margins and optimal nitrogen application

The yield response to $\mathrm{N}$ application differed slightly between the two periods. At very low $\mathrm{N}$ applications, yields tended to be higher for the post-1975 period, particularly for the duplex soil, while at high $\mathrm{N}$ application the yields were mostly higher for the earlier period (Fig. 7); that is, the responsiveness to $\mathrm{N}$ was greater in the pre-1975 period. Southern Cross was the only site which showed a different trend with higher yields for the later periods at all $\mathrm{N}$ applications. Also for duplex soils at the high rainfall sites (e.g. Wongan Hills) yields were higher in the later periods.

Due to the altered response of yield to $\mathrm{N}$ applications and hence a change in the income received per unit input, the gradients of the gross margin response to $\mathrm{N}$ applications also changed. As a result, the optimum $\mathrm{N}$ application (giving the highest gross margin) changed in a number of cases but not all. On the loam, there was a consistent reduction in the optimum $\mathrm{N}$ rate across all locations except for Southern Cross (Table 4). On the duplex soil, the optimum $\mathrm{N}$ rate was lower for four locations and no change occurred at the other locations. On sand, however, the response was mixed. At two locations (Kellerberrin and Buntine), the optimum $\mathrm{N}$ was lower for the post-1975 period while at two other locations (Northam and Southern Cross) the optimum $\mathrm{N}$ rate increased. The gross margins at the optimum $\mathrm{N}$ application were lower on the loam for post-1975 period but increased on the duplex soil. Again, the change on the sand was mixed (Table 4).

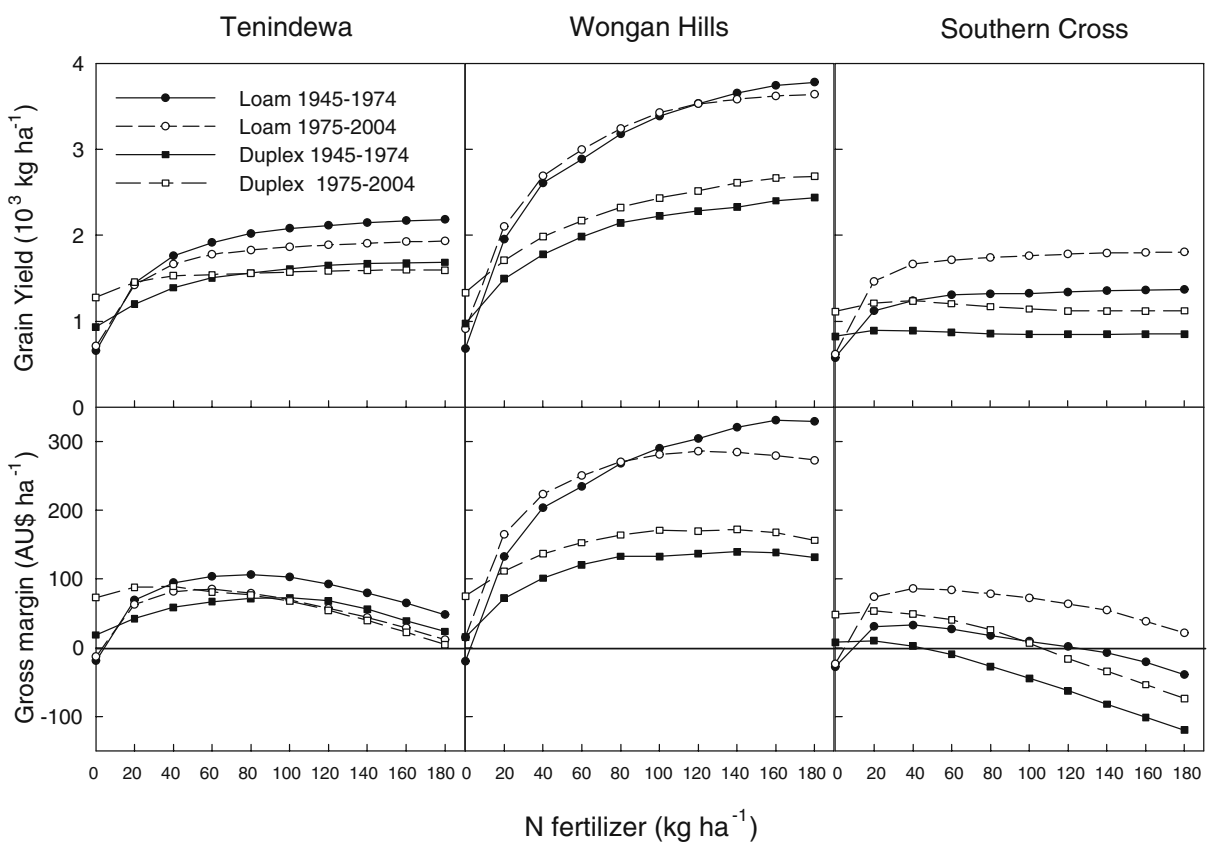

Fig. 7 Simulated impact of the amount of $\mathrm{N}$ fertilizer on grain yield and gross margin for three sites within the Western Australian wheatbelt 


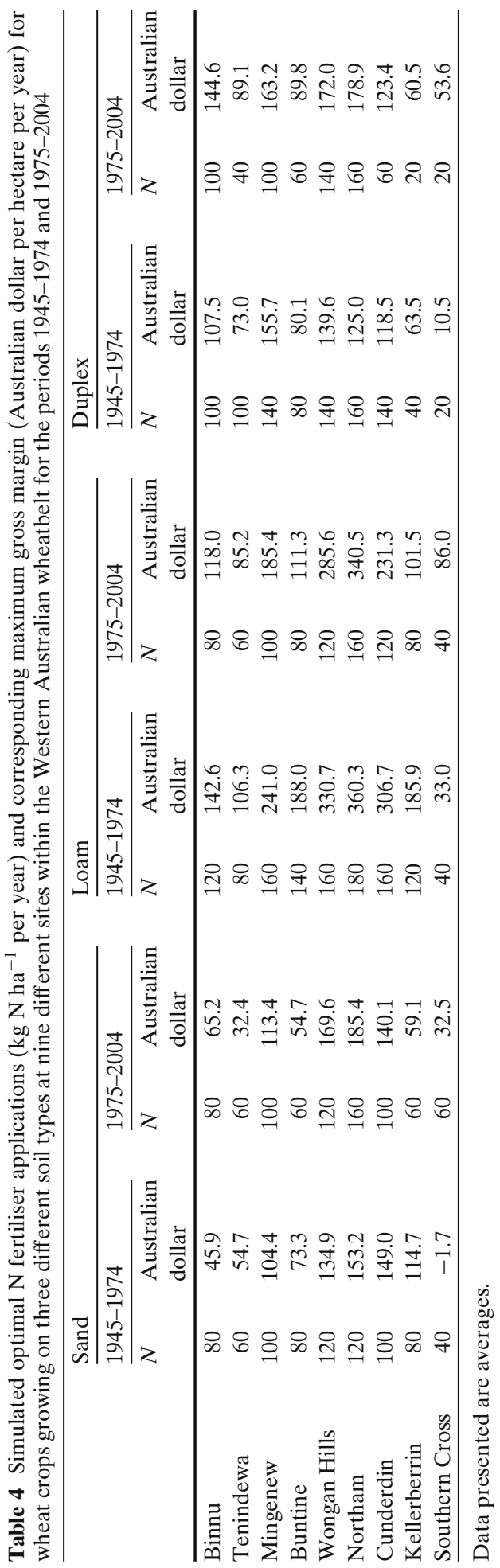




\section{Discussion}

Our results show that the observed lower rainfall in the 1975-2004 period relative to the 1945-1974 period did not result in a reduction of the simulated yield but has potentially a large impact on the hydrology of these farming systems through a large reduction in deep drainage and reduced waterlogging. Rainfall records showed that at all sites except Southern Cross there was a significant reduction in June to July rainfall. On average across sites, the seasonal rainfall was $11 \%$ lower in the last 30 years; yet average yield was not reduced and for a number of sites and soil types there was even a marginal increase in yields. Drainage and nitrate leaching however, have sharply decreased due to the lower rainfall in the last 30 years. It can be expected that this reduction in drainage will reduce the rate at which dryland salinity spreads in the region due to the close correlation between deep drainage and dryland salinity (George et al. 1997; McFarlane and Ruprecht 2005). This is a positive outcome in terms of sustainable production: the lower rainfall resulted in similar production with a reduced negative impact on the environment.

Both the lack of a decline in yield and the sharp reduction in drainage can be attributed to the pattern of the reduction in rainfall that occurred. The reduction in rainfall after 1975 occurred predominantly in June and July. In this environment, these are the months with the highest average rainfall (Figs. 2 and 3). In addition, at this time of the year, the evaporative demand is low due to low radiation, low temperatures, and high humidity (Ward and Dunin 2001). During June and July, the crop is also still relatively small. The combination of a small plant and the cool environment results in low plant water demand and uptake. Hence the risk that a reduction in water supply is likely to limit growth is small. The high water supply and low water use also means significant excess water in June and July, which enters the soil. After the soil profile has reached saturation, further rainfall will result in drainage or runoff. This explains why the reduction in rainfall has resulted in such a dramatic decrease in drainage. The lower drainage was matched by lower leaching. The lower $\mathrm{N}$ loss is likely to have contributed to those situations where simulated yield was seen to be higher in the post-1975 period.

The pattern in the reduction in rainfall also explains the different relationships between rainfall and drainage that were seen for the pre- and post-1975 periods (Fig. 5). For any specified amount of seasonal rainfall, a smaller proportion is likely to fall in June and July (Fig. 3), when rainfall events are more likely to contribute to drainage beyond the root zone.

The conclusion that the lack of a response in yield to the reduced rainfall is due to the distribution of the reduction is also supported by our analysis of the sensitivity of yield to the timing of an artificial reduction in rainfall (Fig. 6). When the rainfall was reduced in either June or July the effect on yield was limited. However a reduction in the May or August rainfall decreased yields much more. In May the soil profile is often still relatively dry and rainfall is needed to wet the soil profile. A reduction in May rainfall also resulted in later sowing opportunities. This explains why May rainfall has more impact on yield than rainfall reduction in June and July, although crop water demand is also usually low in May. In August, plant water demand is higher than in the previous months due to increased solar radiation, temperature and vapor pressure deficit, and a larger canopy size which accelerates the impact of lower rainfall on crop production. Also, from September onwards, rainfall often sharply 
declines and a reduction of rainfall in August increases the risk of severe water stress later in the season.

Due to the high year to year variability in rainfall in Australia, a number of decision support systems have been developed to help farmers to manage climate risk (e.g. Carberry et al. 2002; Meinke and Stone 2005). Many of these decision support systems use all the available historic weather data (often the last 100 years or more) to predict potential yield and yield variability for a specific crop management scenario and location. The predicted yields are then used to assist management decisions, particularly as a basis to manage inputs such as fertilizer. Our analyses show that using all available historic rainfall data can be misleading under conditions of a changing climate. For example, when we used the 1945-1974 rainfall data, different simulated optimal $\mathrm{N}$ applications were derived compared to using the last 30 years of rainfall data. These results indicate the need to test for the impact of climate change when developing decision support tools to assist crop management. It might be more appropriate to only use more recent weather data instead of the full historical record.

Studies using global circulation models (GCM) suggest that south-west Australia is likely to experience further reductions in winter rainfall in the future due to increasing greenhouse gas concentrations in the atmosphere (IOCI 2005). Our results indicate that it cannot be assumed that the reduction in yield will be proportional to the reduction in rainfall, even though analyses of farm yield potential indicate a strong correlation with growing season rainfall (French and Schultz 1984). Further, previous analyses which attempted to estimate the impact of a drying climate by applying a proportional reduction in rainfall across whole seasons are too crude and probably overestimate the impact of climate change on yield and farm productivity (Van Ittersum et al. 2003; John et al. 2005; Ludwig and Asseng 2006). In addition to the question of the distribution of rainfall across the growing season, which we consider here, other parameters such as the size distribution of rainfall events, the interval between rainfall events and rainfall intensity could significantly impact the water balance components and hence crop growth.

Part of these problems can be solved using weather generators or other sophisticated downscaling methods (Semenov 2007; Fowler et al. 2007). In particular, the more advanced weather generators have the capacity to better simulate changes in rainfall distribution. However, the outcome of using such models still depends strongly on the GCM used to drive the changes, although it is possible to use more than one GCM to improve likely predictions. A further complication is that weather generators usually underestimate interannual variability (Semenov et al. 1998; Fowler et al. 2007).

The results of this analysis combined with the known large impact of the drying trend on river flows and water availability for Perth (Power et al. 2005) shows that the impacts of climate change can differ significantly between sectors. Both dryland agriculture and the water supply sector in southern WA depend on rainfall and are affected by rainfall variability. However the $10-15 \%$ reduction in rainfall has reduced water availability for the water supply sector by more than $50 \%$ while the same reduction has had hardly any impact on crop yield in rainfed production systems. These results indicate the need for impact analyses of climate change to be sector specific. Also, proper knowledge of future rainfall distribution is essential for 
accurate analysis of the impact of climate change and the subsequent development of adaptation strategies.

When considering the likely impacts of future climate change, there is a number of further questions which need to be considered in the light of recent rainfall declines. These include: (1) are future changes in rainfall likely to follow the patterns observed to date? and (2) if we assume the reduction will be of a similar manner, to what extent does the crop production system have the capacity to continue to absorb further reductions in winter rainfall? These aspects bring additional uncertainty to estimates of the impact of future climate change on agricultural production.

Acknowledgements We would like to thank Nirav Khimashia for technical support and two anonymous reviewers for comments on a previous version of this paper. This study received financial support from the Grains Research and Development Corporation and the Water for a Healthy Country Flagship of CSIRO.

Open Access This article is distributed under the terms of the Creative Commons Attribution Noncommercial License which permits any noncommercial use, distribution, and reproduction in any medium, provided the original author(s) and source are credited.

\section{References}

Anderson GC, Fillery IRP, Dunin FX, Dolling PJ, Asseng S (1998) Nitrogen and water flows under pasture-wheat and lupin-wheat rotations in deep sands in Western Australia-2. Drainage and nitrate leaching. Aust J Agric Res 49:345-361

Asseng S, Van Herwaarden AF (2003) Analysis of the benefits to wheat yield from assimilates stored prior to grain filling in a range of environments. Plant Soil 256:217-229

Asseng S, Keating BA, Huth NI, Eastham J (1997) Simulation of perched watertables in a duplex soil. In: McDonald AD, McAleer M (eds) MODSIM '97 Proceedings of the international congress on modelling and simulation modelling and simulation society of Australia, vol 2. Canberra ACT, pp 538-543

Asseng S, Keulen H, Stol W, van Keulen H (2000) Performance and application of the APSIM Nwheat model in the Netherlands. Eur J Agron 12:37-54

Asseng S, Fillery IRP, Dunin FX, Keating BA, Meinke H (2001) Potential deep drainage under wheat crops in a Mediterranean climate. I. Temporal and spatial variability. Aust J Agric Res $52: 45-56$

Asseng S, Fillery IRP, Anderson GC, Dolling PJ, Dunin FX, Keating BA (1998a) Use of the APSIM wheat model to predict yield, drainage, and $\mathrm{NO}_{3}^{-1}$ leaching for a deep sand. Aust $\mathrm{J}$ Agric Res 49:363-377

Asseng S, Jamieson PD, Kimball B, Pinter P, Sayre K, Bowden JW, Howden SM (2004) Simulated wheat growth affected by rising temperature, increased water deficit and elevated atmospheric $\mathrm{CO}_{2}$. Field Crops Res 85:85-102

Asseng S, Keating BA, Fillery IRP, Gregory PJ, Bowden JW, Turner NC, Palta JA, Abrecht DG (1998b) Performance of the APSIM-wheat model in Western Australia. Field Crops Res 57: 163-179

Belford RK, Dracup M, Tennant D (1991) Waterlogging limits crop growth on duplex soils. West. Aust J Agric 3:62-65

Carberry PS, Hochman Z, McCown RL, Dalgliesh NP, Foale MA, Poulton PL, Hargreaves JNG, Hargreaves DMG, Cawthray S, Hillcoat N, Robertson MJ (2002) The FARMSCAPE approach to decision support: farmers', advisers', researchers' monitoring, simulation, communication and performance evaluation. Agric Syst 74:141-177

Fowler HJ, Blenkinsop S, Tebaldi C (2007) Linking climate change modelling to impacts studies: recent advances in downscaling techniques for hydrological modeling. Int J Clim 27:1547-1578 
French RJ, Schultz JE (1984) Water use efficiency of wheat in a Mediterranean-type environment. I. The relation between yield, water use and climate. Aust J Agric Res 35:743-764

George R, McFarlane D, Nulsen B (1997) Salinity threatens the viability of agriculture and ecosystems in Western Australia. Hydrogeol J 5:6-21

Hamblin A, Kyneur G (1993) Trends in wheat yields and soil fertility in Australia. Australian Government Publishing Service, Canberra, Australia, p 141

Hochman Z, Van Rees H, Carberry PS, Holzworth D, Dalgliesh NP, Hunt J, Poulton PL, Brennan LE, Van Rees S, Huth NI, Peake AS, McCown RL (2008) Yield Prophet ${ }^{\circledR}$ an Internet-enabled simulation-based system to assist farmers reduce risk in Australia's drought prone environments. $\mathrm{J}$ Exp Bot (in press)

Howden SM, Reyenga PJ, Meinke H (1999) Global change impacts on Australian wheat industry report to the Australian greenhouse office. CSIRO Sustainable Ecosystems, Canberra Australia

IOCI (2002) Indian Ocean climate initiative: climate change in south west western Australia. http://www.ioci.org.au/publications/pdf/IOCI_TechnicalReport02.pdf

IOCI (2005) IOCI reports key findings of recent research into south-western climate, bulletin no. 6. http://www.ioci.org.au/publications/pdf/IOCI_Bulletin6.pdf

John M, Pannell D, Kingwell R (2005) Climate change and the economics of farm management in the face of land degradation: dryland salinity in Western Australia. Can J Agric Econ 53:443-459

Keating BA, McCown RL, Cresswell HP (1995) Paddock-scale models and catchment-scale problems: the role for APSIM in the Liverpool Plains. In: Binning P, Bridgman H, Williams B (eds) MODSIM 95 Proceedings of the international congress on modelling and simulation modelling and simulation Society of Australia Inc., Canberra ACT, pp 158-165

Keating BA, Meinke H, Probert ME, Huth NI, Hills I (2001) NWheat: documentation and performance of a wheat module for APSIM. CSIRO Tropical Agriculture Technical Memorandum. Indooroopilly Queensland CSIRO Tropical Agriculture

Keating BA, Carberry PS, Hammer GL, Probert ME, Robertson MJ, Holzworth D, Huth NI, Hargreaves JNG, Meinke H, Hochman Z, McLean G, Verburg K, Snow V, Dimes JP, Silburn M, Wang E, Brown S, Bristow KL, Asseng S, Chapman S, McCown RL, Freebairn DM, Smith CJ (2003) An overview of APSIM, a model designed for farming systems simulation. Eur J Agron 18:267-288

Ludwig F, Asseng S (2006) Climate change impacts on wheat production in a Mediterranean environment in Western Australia. Agric Sys 90:159-179

Magrin GO, Travasso MI, Rodriguez GR (2005) Changes in climate and crop production during the 20th century in Argentina. Clim Chang 72:229-249

McFarlane DJ, Ruprecht J (2005) How salinity has changed Indian Ocean climate initiative climate note 11/05. http://www.ioci.org.au/publications/pdf/IOCIclimatenotes_11.pdf

McFarlane DJ, Williamson DR (2002) An overview of water logging and salinity in southwestern Australia as related to the 'Ucarro' experimental catchment. Agric Water Manag 53:5-29

McFarlane DJ, George RJ, Caccetta PA (2004) The extent and potential area of salt-affected land in Western Australia estimated using remote sensing and digital terrain models. In: 1st national salinity engineering conference, Perth, Western Australia, 9-12 November 2004

Meinke H, Stone R (2005) Seasonal and inter-annual climate forecasting: the new tool for increasing preparedness to climate variability and change in agricultural planning and operations. Clim Chang 70:221-253

Monteith JL (1988) Does transpiration limit the growth of vegetation or vice versa? J Hydrol 100:57-68

Power S, Sadler B, Nicholls N (2005) The influence of climate science on water management in Western Australia-lessons for climate scientists. Bull Am Meteorol Soc 86:839-844

Probert ME, Keating BA, Thompson JP, Parton WJ (1995) Modelling water, nitrogen, and crop yield for a long-term fallow management experiment. Aust J Exp Agric 35:941-950

Probert ME, Carberry PS, McCown RL, Turpin JE (1998) Simulation of legume-cereal systems using APSIM. Aust J Agric Res 49:317-327

Ritchie JT, Godwin DC, Otter-Nacke S (1995) CERES-wheat-a simulation module of wheat growth and development Michigan State University Agristars publication number: YM-U304442-JSC-18892

Semenov MA (2007) Development of high-resolution UKCIP02-based climate change scenarios in the UK. Agric For Meteorol 144:127-138 
Semenov MA, Brooks RJ, Barrow EM, Richardson CW (1998) Comparison of the WGEN and LARS-WG stochastic weather generators for diverse climates. Clim Res 10:95-107

Smith IN, McIntosh P, Ansell TJ, Reason CJC, McInnes K (2000) Southwest Western Australian winter rainfall and its association with Indian Ocean climate variability. Int J Climatol 20: 1913-1930

Turner NC, Ward PR (2002) The role of agroforestry and perennial pasture in mitigating water logging and secondary salinity: summary. Agric Water Manag 53:271-275

Turner NC, Asseng S (2005) Productivity, sustainability and rainfall-use efficiency in Australian rainfed Mediterranean agricultural systems. Aust J Agric Res 56:1123-1136

Van Ittersum MK, Howden SM, Asseng S (2003) Sensitivity of productivity and deep drainage of wheat cropping systems in a Mediterranean environment to changes in $\mathrm{CO}_{2}$, temperature and precipitation. Agric Ecosyst Environ 97:255-273

Ward PR, Dunin FX (2001) Growing season evaporation from duplex soils in south-western Australia. Agric Water Manage 50:141-159 